The droplets are more frequently found scattered within large chromophobes but also within eosinophiles, and even, although rarely, within some cyanophiles. These large chromophobes correspond to the $\gamma$ - and $\varepsilon$-cells of Romeis ${ }^{7}$, and this author has already observed these droplets, which he has described as intracellular colloid droplets. Indeed, we frequently observe these droplets falling into the colloid vesicles. This observation and the strongly positive reaction of these inclusions confirm Romeis's opinion.

The periodic acid-Schiff method confirms the mucoprotein nature of the cyanophile granules; it proves that these granules are quite different from the colloid droplets, the latter giving the reaction more strongly, and indicates the mechanism of colloid formation within the cells and its discharge into vesicles or into the lumina of the sinusoids.

MARC HERLANT

Laboratoire d'Anatomie Pathologique,

Université libre de Bruxelles. May 17.

${ }^{1}$ Herlant, M., Bull. Acad. Roy. Sci., 28, 588 (1942); Arch. Biol. 54, 227 (1943).

${ }^{2}$ Hartman, C. G., and Benz, F., Nature, 142, 115 (1939).

${ }^{3}$ Evans, H. M., Fraenkel-Conrat, H. L., Simpson, M. E., and Li, Ch. Science, 89, 249 (1939).

+ Hotchkies, R. D., Arch. Biochem., 16, 131 (1948).

$\checkmark$ McManus, J. F. A., Nature, 158, 202 (1946).

- Pearse, A. G. E., Nature, 162, 651 (1948).

'Romeis, B., "Hypophyse", in v. Möllendorf's "Handbuch der mikrosk. Anat. des Mensches" (Julius Springer, Berlin, 1940).

\section{Sympathomimetic Substance in Human Lumbar Sympathetic Chain}

IN 1939, Lissak ${ }^{1}$ showed that extracts of sympathetic nerves contained a sympathomimetic substance with an adrenaline-like action on various biological preparations. In a series of papers, von Euler ${ }^{2,3,4}$ has demonstrated that this type of extract is largely noradrenaline. His chief sources of material were cattle and horses. Lissak ${ }^{5}$ further showed that if a postganglionic sympathetic nerve was stimulated electrically, and the cut end of the nerve allowed to hang beneath the surface of acidified saline during the passage of the current, the saline assumed sympathomimetic properties from diffusion into it of an adrenaline-like substance from the nerve.

A series of five specimens of human lumbar sympathetic chain were obtained by courtesy of various surgical colleagues at the Cardiff Royal Infirmary, to whom thanks are due. The specimens were taken at once from the operating theatre wrapped in gauze moistened with saline. They were washed in saline, dried gently and suspended from electrodes. Four of the specimens consisted of lumbar sympathetic ganglia $L_{4}$ and $L_{5}$, with a length of chain between and a stump of chain beyond each ganglion. These specimens were suspended from the middle and threaded through holes in filter paper, which was caused to ring the surface of the nerve closely, just above the ganglia; this prevented anything dripping from the nerve surface to the fluid beneath. The cut ends dipped below the surface of $2.0 \mathrm{ml}$. of 0.65 per cent saline at $p \mathrm{H} 4$ (hydrochloric acid). The fifth specimen included ganglion $L_{3}$, which was very close to $L_{4}$. It was suspended by $L_{3}$ and $L_{4}$ from the electrodes and the cut end distal to $L_{5}$ submerged. Stimulation was carried out for fifteen minutes from a coil at $12 \mathrm{~cm}$. distance. The fluid was taken and a portion neutralized and $0.2 \mathrm{ml}$. administered at once to a frog's heart perfused by Hartung's method ${ }^{6}$.
In all cases the fluid was sympathomimetic, that is, it produced a quickening and increase in force and amplitude of the beat of the heart. An equivalent effect was produced by $l$-adrenaline $0.01 \mu \mathrm{gm}$. or l-noradrenaline $0.1 \mu \mathrm{gm}$. The fluid was stored at $4^{\circ} \mathrm{C}$. and given intravenously to chloralosed cats with a high blood-pressure as soon as convenient, usually next day. $1.0 \mathrm{ml}$. of fluid given slowly produced a rise of blood pressure of about $15 \mathrm{~mm}$. mercury, but little or no effect on the non-pregnant uterus. $0.05 \mu \mathrm{gm}$. of $l$-adrenaline (adrenaline equivalent of $1.0 \mathrm{ml}$. fluid from the frog-heart test) caused a fall in blood pressure and relaxation of the non-pregnant uterus; $l$-noradrenaline $0.5 \mu \mathrm{gm}$. caused a rise in blood pressure and no effect on the uterus. Saline controls had no effect. All three substances inhibited the movements of isolated rabbit intestine.

It was concluded that post-ganglionic fibres of the human sympathetic chain secrete a sympathomimetic substance which more closely resembles noradrenaline than adrenaline.

The specimens were dried, the ganglia cut from the fibres and the parts weighed. They were triturated with washed powdered glass and extracted with $1.0 \mathrm{ml}$./gm. wt. of acid saline $(p \mathrm{H} 3 \cdot 0)$. The filtrate from this was dialysed through a collodion membrane in a centrifuge at medium speed for one hour, against an equal volume of acid saline. The latter fluid was then taken, neutralized and tested as before. Extract of sympathetic ganglia inhibited the frog heart, and frequently stimulated it after initial inhibition. Atropine abolished this inhibition. Extracts of ganglia also caused a fall in blood pressure in the cat, not entirely abolished but reduced by atropine, and variable effects on rabbit intestine. Extracts of sympathetic chain were sympathomimetic and gave mixed and confusing effects which suggested the presence of a mixture of adrenaline and noradrenaline. After dihydroergotamine the effect on the blood pressure was reduced or largely annulled but not reversed. The administration of an antihistamine compound $2786 R P$ did not affect the results. The actions of extracts of sympathetic chain fibres resembled those of extract of phæochromocytoma, as described recently by Holton ${ }^{7}$ and confirmed by Euler and Hamberg ${ }^{8}$. These authors confirmed the presence of a mixture of noradrenaline and adrenaline by paper chromatography. The biological reactions they describe were similar to those found in acid extract of normal sympathetic chain or in acid extract of an adrenal tumour (supplied by courtesy of Prof. J. Gough, Pathology Department, Cardiff Royal Infirmary), in which it was estimated by biological assay that the medullary tumour substance contained $10.6 \mathrm{mgm}$./gm. of $l$-noradrenaline and $2.7 \mathrm{mgm}$./gm. of $l$-adrenaline equivalents.

It is concluded that human sympathetic nerve chain contains an extractable sympathomimetic 'ergone' which may be a mixture of adrenaline and noradrenaline.

Department of Pharmacology,

Welsh National School of Medicine, Cardiff. May 25.

${ }^{1}$ Lissak, K., Amer. J. Physiol., 125, 778 (1939).

2 Euler, U. S. von, Nature, 158, 18 (1945).

${ }^{3}$ Euler, U. S, von, Acta Physiol. Scand., 11, 168 (1946).

4 Euler, U. S. von, Acta Physiol. Scand., 12, 73 (1946).

${ }^{5}$ Lissak, K., Amer. J. Physiol., 127, 263 (1939).

' Hartung, K., Archiv. f. exper. Path. u. Pharmakol., 66, 1 (1911).

Holton, P., Nature, 163, 217 (1949).

${ }^{8}$ Euler, U. S. von, and Hamberg, U., Nature, 163, 642 (1949). 